\title{
Avaliação da Qualidade do Leite Fortificado com Cálcio e Ferro
}

\author{
Berchó Franco, Divino Carlos, Edilaine Santos, José Rubens \\ Gonçalves \& Renata M. Gonçalves
}

Por ser considerado um alimento rico em proteínas e outros nutrientes como minerais, além de acessível a toda população, o leite vem apresentando vários interesses de mercado. Com a finalidade de reforçar seu valor nutricional, especialmente de ferro, revelado pelos resultados analíticos como elemento com teor mais baixo no leite, surge a necessidade de enriquecimento desse alimento. Este trabalho teve como objetivo avaliar as condições do leite fortificado com cálcio e ferro, considerando as normas do Ministério da Agricultura, Pecuária e Abastecimento.

Palavras-chave: absorção atômica; minerais; leite pasteurizado.

Since it is a food rich in protein and other nutrients such as minerals, and accessible to the whole population, the milk has been presenting various interests of the market. Aiming to enhance their nutritional value especially iron, revealed by the analytical results as element with lower content in milk, the need arises for enrichment of the feed. This study aimed to assess the conditions of milk fortified with calcium and iron, considering the standards of the Ministry of Agriculture, Livestock and Supply.

Keywords: atomic absorption; minerals; pasteurized milk. 


\section{Introdução}

De acordo com o Regulamento de Inspeção Industrial e Sanitária dos Produtos de Origem Animal do Ministério da Agricultura, Pecuária e Abastecimento ${ }^{1}$, entende-se por leite, sem outra especificação, o produto oriundo da ordenha completa, ininterrupta, em condições de higiene de vacas sadias, bem alimentadas e descansadas. O leite de outros animais deve denominar-se segundo a espécie de que proceda.

Segundo $\mathrm{CECCHI}^{2}$, leite é um produto íntegro, não alterado e sem colostro, higienicamente ordenhado de fêmeas mamíferas. É secretado pelas glândulas mamárias e alimento indispensável aos mamíferos nos primeiros meses de vida. Ele deve ter o aspecto líquido, opaco, não deve apresentar grumos, coágulos, flóculos ou mucosidade, e a camada de gordura não deve ser filante. A cor deve ser branca ou levemente amarelada. Para a fabricação de produtos lácteos, deve ser de boa qualidade, pois a mesma está relacionada às condições de sanidade dos rebanhos. A conservação e o transporte constituem importantes fases do processamento do leite, nas quais se definem os níveis de qualidade dos produtos a serem elaborados.

Dada a importância e a necessidade desta bebida para o consumo humano, por ser considerado um alimento com alto valor nutritivo contendo proteínas, cálcio, vitaminas e outros nutrientes, além de acessível a toda a população. Muitos são os avanços relacionados às etapas de produção, processamento e distribuição do leite que tem favorecido ainda mais o consumo humano ${ }^{3}$. Com a finalidade de reforçar o valor nutritivo de alguns alimentos e ou prevenir deficiências demonstradas em um ou mais nutrientes da alimentação da população de um grupo específico, surge a necessidade de enriquecimento dos alimentos, entre eles o leite bovino ${ }^{4}$.

Assim, este estudo teve como objetivo verificar as condições das embalagens e rotulagens dos leites fortificados com cálcio e ferro, quantificando os minerais cálcio e ferro, comparando-os ao leite não fortificado, segundo as normas do Ministério da Agricultura, Pecuária e Abastecimento.

\section{CARACTERÍSTICAS FÍSICO-QUÍMICAS DO LEITE}

O leite é um liquido branco, opaco, duas vezes mais viscoso que a água, de sabor ligeiramente açucarado e de odor pouco acentuado ${ }^{5}$. O leite produzido pelo animal varia quanto ao volume e quanto à relação entre os seus diversos componentes. As variações quanto à composição do leite dependem dos fatores: espécie animal, raça, individualidade animal, intervalo entre ordenhas, variação durante a ordenha, diferenças entre os quartos, período de lactação, influência das estações, alimentação, temperatura, doenças, idade do animal e condições climáticas ${ }^{6}$.

É uma emulsão de glóbulos graxos, estabilizado por substâncias albuminóides num soro que contém em solução: um açúcar - a lactose, matérias protéicas, sais minerais e orgânicos e pequenas quantidades de vários produtos, tais como: lecitina, uréia, aminoácidos, ácido cítrico, ácido láctico, ácido acético, álcool, lactocromo, vitaminas, enzimas, e outros ${ }^{3}$.

As proteínas do leite vêm despertando interesse cada vez maior, sob o ponto de vista econômico e nutricional. A demanda crescente de derivados lácteos providos de teores elevados deste componente, a exemplo de queijos e outros produtos alimentícios, demonstra uma maior conscientização do povo quanto ao uso de proteínas balanceadas, de sabor agradável e a baixo custo. $\mathrm{O}$ reconhecimento do valor nutricional das proteínas lácteas advém do fato delas conterem todos os aminoácidos essenciais ou indispensáveis nas proporções requeridas para crescimento e manutenção do organismo humano. Convém ressaltar que o leite de vaca contém duas vezes mais proteínas que o leite humano ${ }^{6}$. Na Tabela 1 podem ser verificadas as quantidades em minerais do leite bovino.

\section{SAÚdE E A FORTIFICAÇÃO DE ALIMENTOS}

Os costumes alimentares e as necessidades nutricionais do homem contemporâneo começaram a ser estabelecidos no passado pré-histórico, e desde então sofrem sucessivas adaptações. Mudanças para hábitos pouco saudáveis constituem desvantagens para a saúde e estão associadas muitas vezes aos desvios ponderais e ao desenvolvimento de deficiências nutricionais múltiplas ou específicas ${ }^{7}$.

A alimentação e a nutrição constituem requisitos básicos para a promoção da saúde, possibilitando a afirmação plena do potencial de crescimento e desenvolvimento humano com qualidade de vida. No plano individual e em escala coletiva esses requisitos estão consignados na Declaração Universal dos Direitos Humanos promulgada há cerca de 50 anos, os quais foram 
posteriormente reafirmados pelo Pacto Internacional sobre Direitos Econômicos, Sociais e Culturais incorporados à legislação nacional. Através de uma dieta adequada em quantidade e qualidade, o organismo adquire a energia e os nutrientes necessários para o desempenho de suas funções e para a manutenção de um bom estado de saúde, podendo ainda prevenir numerosas doenças e morte prematura ${ }^{7}$.

Tabela 1. Quantidades de minerais presentes no leite bovino.

\begin{tabular}{|c|c|}
\hline Minerais & Porcentagem (\%) \\
\hline Cálcio & 0,10 \\
\hline Fósforo & 0,10 \\
\hline Potássio & 0,15 \\
\hline Magnésio & 0,012 \\
\hline Cloro & 0,10 \\
\hline Sódio & 0,05 \\
\hline Cobre & 0,00002 \\
\hline Ferro & 0,005 \\
\hline Enxofre & 0,03 \\
\hline
\end{tabular}

Fonte: PINHEIRO e MOSQUIM (1991).

Em um país como o Brasil em que as desigualdades regionais são expressivas, é importante destacar que a promoção da alimentação saudável pressupõe a necessidade da definição de estratégias voltadas à saúde e ao cuidado nutricional ${ }^{8}$. Neste sentido, as carências de micronutrientes configuram desafios para políticas de saúde pública na área de Alimentação e Nutrição.

Com isso, a fortificação dos alimentos pode ser apontada como uma estratégia mundial de combate às carências nutricionais, com o objetivo de minimizar a prevalência de deficiências por micronutrientes 9 .

\section{CONTROLE DE QUALIDADE DO LEITE}

Promover o controle de qualidade do leite por meio da avaliação físico-química é muito importante, pois se constitui de análises rotineiras para pesquisar e garantir a qualidade do produto fornecido aos consumidores pelas indústrias. O leite contém microrganismos e estes quando alterados, podem mudar os resultados das análises físicoquímicas. Por isso, é necessário o monitoramento constante por parte dos laboratórios e órgãos fiscalizadores, para garantir a inocuidade do produto $^{10}$.

Verificar as embalagens com os devidos rótulos, para saber se permanece em estado de conservação adequado, bem como se possuem descrições fidedignas com relação aos conteúdos dos produtos, são itens necessários para promover e garantir o controle de qualidade dos alimentos. Também avaliar se existe presença de contaminantes no leite, como por exemplos os metais pesados cádmio e chumbo, que são prejudiciais à saúde dos seres vivos, além de cumulativos ao longo do tempo ${ }^{11,12}$.

\section{INGESTÃO DIÁRIA RECOMENDADA (IDR) DOS MINERAIS}

Segundo o Regulamento Técnico sobre a Ingestão Diária Recomendada (IDR) de proteínas, vitaminas e minerais13, a IDR é a quantidade que deve ser consumida diariamente para atender às necessidades nutricionais da maior parte dos grupos de pessoas de uma população sadia, preconizados por órgãos de referência como o Institute of Medicine. Na Tabela 2 é possível conferir a $\mathrm{IDR}^{14}$ dos minerais cálcio e ferro para diferentes faixas etárias e momentos biológicos.

\section{O CÁLCIO}

A importância da adequação da ingestão de cálcio, especialmente em momentos biológicos que requerem maior aporte do mineral, tem sido crescentemente reconhecida. O cálcio é um elemento fundamental ao organismo e sua importância está relacionada às funções que desempenha principalmente na saúde óssea, desde a formação até a manutenção de sua estrutura, assim como na mineralização. Esse mineral também regula diversos processos orgânicos como a excitabilidade neuromuscular, coagulação sanguínea, integridade e transporte por meio das membranas, reações enzimáticas,

Tabela 2. Ingestão Diária Recomendada de cálcio e ferro para adultos e crianças.

\begin{tabular}{|c|c|c|c|c|c|c|}
\hline Nutrientes & $\mathbf{1 - 3}$ anos & $\mathbf{4 - 6}$ anos & $\mathbf{7 - 1 0}$ anos & Gestantes & Lactantes & Adultos \\
\hline Cálcio & $500 \mathrm{mg}$ & $600 \mathrm{mg}$ & $900 \mathrm{mg}$ & $1200 \mathrm{mg}$ & $1000 \mathrm{mg}$ & $1000 \mathrm{mg}$ \\
\hline Ferro & $6 \mathrm{mg}$ & $6 \mathrm{mg}$ & $9 \mathrm{mg}$ & $27 \mathrm{mg}$ & $15 \mathrm{mg}$ & $14 \mathrm{mg}$ \\
\hline
\end{tabular}

Fonte: Institute of Medicine (2003) ${ }^{12}$. 
liberação de hormônios e neurotransmissores, assim como ação intracelular de diversos hormônios ${ }^{15}$.

A única fonte deste mineral disponível para o organismo humano é a dieta, sendo importante garantir uma ingestão mínima para a completa maturação dos ossos. Existem poucas fontes consideradas ótimas de cálcio dietético, representadas principalmente pelo grupo do leite e seus derivados. Embora seja facilmente encontrado em produtos lácteos, esse nutriente tem seu aporte bastante prejudicado em indivíduos portadores de condições de saúde específicas, como no caso dos alérgicos a leites e dos intolerantes à lactose; fato que já impulsionou estudos na área da fortificação de produtos de origem vegetal ${ }^{16}$.

O baixo consumo de cálcio é considerado um problema nutricional presente e potencial no Brasil, podendo causar além da osteoporose no adulto, o raquitismo nas crianças. A osteoporose é uma enfermidade que afeta a saúde óssea, caracterizada por maior fragilidade e consequente aumento do risco de fraturas. O ganho de massa óssea ao longo da adolescência, especialmente para meninas, é fundamental para evitar a referida doença em idades avançadas. A predisposição para a mesma tem início na infância e na adolescência, momentos biológicos nos quais a baixa ingestão desse mineral resulta em menor mineralização óssea, quando esta é comparada à de indivíduos da mesma faixa etária que tiveram ingestão adequada de cálcio ${ }^{16}$.

A osteoporose é umas das principais morbidades que acometem a mulher no climatério, causando, por conseguinte, impactos negativos tanto na saúde pública como na economia do país, em função dos custos diretos e indiretos com essa patologia. Uma feição comum do processo osteoporótico é o balanço de cálcio negativo, devido à maior perda do que retorno deste mineral no esqueleto. A ingestão de cálcio a partir do nascimento, principalmente na infância e juventude, aliada ao exercício físico regular, é um fator de prevenção de uma posterior desmineralização óssea ${ }^{17}$.

O cálcio pode ser obtido a partir de alimentos que são naturalmente ricos no mineral (como leite, queijos, iogurtes), de produtos enriquecidos e/ou de suplementos. Os suplementos minerais mais utilizados em processos industriais de enriquecimento são: carbonato, citrato, fosfato (dibásico e tribásico), lactato e lactogluconato de cálcio $^{15}$, formas consideradas bastante solúveis. Quanto maior a solubilidade de um sal de cálcio maior a sua biodisponibilidade, visto que a solubilidade dos sais orgânicos é muito maior que a dos sais inorgânicos.

Estimular um adequado consumo de cálcio durante os ciclos de vida da pessoa parece ser uma importante estratégia de prevenção em relação à osteoporose. Enriquecer alimentos isentos de leites e seus derivados com cálcio pode ser útil também para pacientes portadores de intolerância à lactose, ou mal-absorvedores deste dissacarídio ${ }^{8}$.

\section{O FERRO}

O ferro foi reconhecido como um nutriente essencial há mais de um século. A deficiência nutricional deste micromineral e a anemia ferropriva ainda permanecem comuns na atualidade, apesar da diversidade de alimentos fontes deste nutriente, sejam eles processados ou não. Especialmente para as mulheres em fase gestacional, as lactentes e para as crianças recém-nascidas até dois anos de vida, o ferro deve ser consumido em maior quantidade para suprir as necessidades dessas fases, sendo a alimentação e enriquecimento alimentar as peças chaves para alcançar a recomendação desse nutriente ${ }^{18}$.

A deficiência de ferro é geralmente resultado do aporte insuficiente ou da má absorção do mineral, ou por uma combinação de ambos. A condição denominada anemia ferropriva chega a ser responsável por $95 \%$ das anemias, quadro muito prevalente no Brasil, preferencialmente em crianças, mulheres em idade fértil e em gestantes ${ }^{13}$.

O combate à deficiência de ferro, devido a sua elevada prevalência mundial e consequências sobre o crescimento, desenvolvimento e mortalidade da população infantil, principalmente em menores de dois anos, é uma das prioridades no planejamento de Programas de Nutrição em saúde pública. Esse distúrbio resulta da combinação de múltiplos fatores etiológicos. Entre as causas imediatas dessa carência destacam-se a baixa ingestão de alimentos fontes de ferro, a baixa absorção do ferro ingerido e as perdas desse micronutriente devido a infecções parasitárias. As infecções helmínticas cuja prevalência é elevada nos países em desenvolvimento, especialmente entre crianças e adolescentes, podem comprometer os níveis nutricionais de ferro ${ }^{19}$.

A anemia traz inúmeras consequências para o organismo de indivíduos de ambos os sexos e de todas as idades. $\mathrm{Na}$ infância, fase da vida em que existe um 
aumento das necessidades nutricionais, a anemia tem efeitos negativos sobre o desenvolvimento ponderal e sobre a aprendizagem escolar. Nos adultos, o principal impacto é a diminuição da capacidade produtiva. Em gestantes, os efeitos da anemia por deficiência de ferro incluem maior risco de morbidade e mortalidade materna, e nos recém-natos com baixo peso ao nascer ${ }^{19}$.

Deste modo, o consumo concomitante de alimentos fonte de ferro e vitamina C deve ser estimulado, considerando-se que dietas com quantidades insuficientes de ácido ascórbico podem agravar casos de anemia ferropriva. A fortificação dos alimentos é aceita como o melhor meio de combater a anemia em pré-escolares, motivo pelo qual diferentes produtos alimentícios com esta finalidade têm sido desenvolvidos. Em função do possível aumento da biodisponibilidade do ferro promovido pela vitamina $\mathrm{C}$, a adição destes nutrientes em produtos fortificados pode representar uma boa estratégia no desenvolvimento desta categoria de produtos ${ }^{19}$.

\section{Material e Métodos}

Foram colhidas aleatoriamente 30 marcas diferentes de leite bovino pasteurizado, fortificado com cálcio e ferro, em vários supermercados da cidade de Anápolis e Goiânia. As amostras foram conduzidas em caixa isotérmica resfriada em gelo até o laboratório da Faculdade de Tecnologia - FATEC SENAI ROBERTO MANGE. Examinaramse cuidadosamente as condições das embalagens e das amostras. Retiraram-se partes representativas delas e em quantidades suficientes para as analises em duplicatas, e também para eventuais repetições. Conservou-se em refrigeração e longe de contaminantes.

As mesmas foram homogeneizadas antes de se iniciar as análises. As análises foram divididas em qualitativas e quantitativas. Para a determinação do cálcio e ferro utilizou-se um equipamento de absorção atômica, Marca Perkin Elmer, Modelo AAnalyst 200. Todas as análises seguiram as Normas Analíticas do Ministério da Agricultura, Pecuária e Abastecimento ${ }^{20}$.

\section{PREPARO E PROCESSAMENTO DAS AMOSTRAS DE LEITE PARA AS ANÁLISES}

Em todas as amostras foram verificadas as condições da embalagem e rótulos contidos nas mesmas para conferir com os resultados das análises posteriormente.
As amostras foram colocadas à temperatura ambiente e homogeneizadas previamente por agitação manual. Foram utilizados controles, chamados de brancos, que passaram pelas mesmas etapas de preparo das amostras, inclusive os tratamentos térmicos.

Alíquotas de cerca de $5 \mathrm{~g}$ de amostras de leite pasteurizado foram pesadas em cadinhos de porcelana de $150 \mathrm{~mL}$. A seguir, realizou-se a evaporação e secagem do leite em estufa de secagem e esterilização, temperatura de $95^{\circ} \mathrm{C}$. Posteriormente, procedeu-se a pré queima em chapa elétrica de temperatura regulável a $200^{\circ} \mathrm{C}$. Finalmente, foram levadas ao forno mufla para incineração a $500^{\circ} \mathrm{C}$ por horas. Após resfriamento, as cinzas foram umedecidas com $2 \mathrm{~mL}$ de ácido nítrico a $50 \%$, e 3 horas. Imediatamente depois foram submetidas à secagem em chapa elétrica a $100^{\circ} \mathrm{C}$ e calcinadas a $500^{\circ} \mathrm{C}$ por 3 horas. As cinzas completamente brancas foram dissolvidas em ácido nítrico a 50\%. Todo o conteúdo do cadinho foi transferido quantitativamente para balões volumétricos de $50 \mathrm{~mL}$ sob filtração em papel de filtro, filtração média, completando-se o volume com água destilada deionizada, com grau de pureza $\mathrm{EAA}^{20}$.

\section{DETERMINAÇÃO DE CÁLCIO}

Preparação de padrão de cálcio: transferiu-se um conteúdo de uma ampola (1g de cálcio) para um balão volumétrico de $1000 \mathrm{~mL}$. Completou-se o volume com água deionizada e homogeneizou-se. A partir desta solução, usaram-se concentrações de trabalho adequadas: $2 \mathrm{mg} / \mathrm{L}, 4 \mathrm{mg} / \mathrm{L}, 8 \mathrm{mg} / \mathrm{L}$, e $10 \mathrm{mg} / \mathrm{L}$, adicionando $1 \mathrm{~mL}$ de ácido clorídrico e $8 \mathrm{~mL}$ de solução de lantânio a 5\%, e completou-se o volume com água destilada deionizada.

Preparação do Branco: Utilizou-se em um balão volumétrico de $100 \mathrm{~mL}$ a mesma quantidade de ácido clorídrico e lantânio utilizada na amostra.

Adequou-se a concentração de cálcio da amostra à curva padrão previamente estabelecida. Adicionou-se a solução de lantânio correspondente a $10 \%$ do volume final da última diluição e completou-se o volume com água destilada deionizada. Em seguida, usou-se um equipamento de absorção atômica, usando o branco para zerar o equipamento e as soluções padrões para ajuste e otimização. O comprimento de onda, corrente da lâmpada, fenda e faixa de trabalho foram estabelecidos de acordo com o manual do equipamento e recomendação do fabricante. 


\section{DETERMINAÇÃO DE FERRO}

Preparação padrão de ferro: dissolveu-se $1 \mathrm{~g}$ de ferro (ampola titrisol) em balão volumétrico de $1000 \mathrm{~mL}$ e completou-se o volume com água deionizada. A partir desta solução, diluindo-a obtivemos a concentração de trabalho de $4 \mathrm{mg} / \mathrm{L}$ de ferro. Preparação do branco: diluiu-se em um balão volumétrico de $100 \mathrm{~mL}$ a mesma quantidade de ácido clorídrico utilizada na solução da amostra. Completou-se o volume com água deionizada.

Houve outras diluições, conforme o teor de ferro da amostra. A leitura foi realizada em espectrofotômetro de absorção atômica a 248,3nm, usando o branco para zerar o aparelho e as soluções padrões para calibração.

\section{ANÁLISE ESTATÍSTICA}

Foram calculados os parâmetros de tendência central (média e mediana) e de dispersão, desvio padrão, valores máximo e mínimo dos minerais. Também foram feitos gráficos de frequência para comparação de cada mineral avaliado, considerando os dois tipos de leite (fortificado e não fortificado). A regressão linear foi aplicada entre as leituras dos padrões, com o intuito de verificar a exatidão em relação às leituras das amostras, estabelecendo a dispersão das médias e desvio padrão em relação à curva de calibração específica para cada elemento em estudo.

\section{Resultados e Discussão}

Das amostras avaliadas, todas foram consideradas padronizadas com relação aos aspectos de conservação e qualidade dos produtos, além de conferir com as descrições do rótulo, os valores obtidos das análises dos minerais. Como ainda não existem no mercado disponibilizadas muitas marcas de leites fortificados com esses nutrientes pesquisados, o número amostral foi reduzido, porém as avaliações contemplaram todo o material obtido nos maiores estabelecimentos da região de Anápolis e Goiânia.

$\mathrm{Na}$ Tabela 3, nota-se que a média de cálcio do leite fortificado pode contribuir para uma alimentação mais rica deste elemento, especialmente na fase de crescimento e formação, mesmo que a quantidade de cálcio não seja tão elevada a ponto de suprir totalmente as recomendações diárias deste nutriente, que é considerada alta. A suplementação de cálcio é mais importante quando se utiliza outras fontes deste mineral na alimentação, que não sejam produtos do leite e derivados, para atender a exigência para os indivíduos do sexo feminino com disfunção hormonal, em que os estoques no organismo ficam prejudicados, especialmente em idade mais avançada. Nesta fase, há necessidade de utilizar suplementos e fortificação com o cálcio para reduzir as deficiências e carências nutricionais.

Tabela 3. Teores de cálcio ( $\mathrm{mg} / \mathrm{L})$ em leite fortificado bovino e medidas estatísticas.

\begin{tabular}{|c|c|}
\hline Parâmetro & Cálcio \\
\hline Média & 8,91 \\
\hline Erro padrão & 0,30 \\
\hline Mediana & 8,53 \\
\hline Modo & 7,91 \\
\hline Desvio padrão & 1,52 \\
\hline Variância da amostra & 2,32 \\
\hline Curtose & 0,54 \\
\hline Assimetria & 1,32 \\
\hline Intervalo & 5,14 \\
\hline Mínimo & 7,21 \\
\hline Máximo & 12,35 \\
\hline
\end{tabular}

Quando se comparam os dados analíticos obtidos de cálcio e ferro com as concentrações declaradas nas embalagens, os leites fortificados encontram-se conforme o mencionado no rótulo pelo fabricante, o que demonstra que o nutriente realmente foi adicionado ao produto. Sendo assim, pode ser uma boa opção para alimentação mais adequada em relação ao cálcio, podendo contribuir para a redução de carência nutricional desse mineral no ser humano.

Nas Figuras 1 e 2, pode-se perceber claramente que os leites fortificados possuem maiores composições de cálcio e ferro, permitindo a afirmação que o enriquecimento alimentar é essencial para otimizar as concentrações e absorções desses nutrientes no organismo humano e animal. Sendo assim, para uma pessoa que não possui alimentação bastante variada e equilibrada o suficiente para alcançar a recomendação diária de nutrientes, o leite fortificado bem como outros produtos, podem ser boas alternativas na dieta diária. 


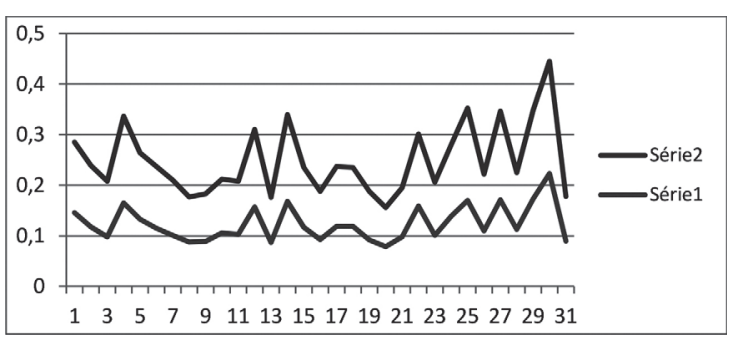

Figura 1. Comparação dos resultados obtidos entre teores de cálcio (Série 1: leite fortificado e série 2: leite não fortificado).

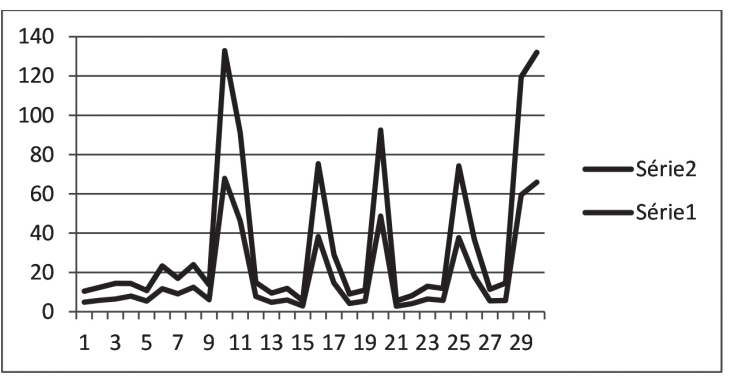

Figura 2. Comparação dos resultados obtidos entre teores de ferro (Série 1: leite fortificado e série 2: leite não fortificado).

Conforme resultados obtidos para o ferro (Tabela 4) constata-se que a quantidade não atende às necessidades nutricionais requeridas para o ser humano, conforme a $\mathrm{RDI}^{14}$, especialmente na fase de crescimento e formação. Sabe-se que o leite não é uma fonte muito rica em ferro naturalmente, provavelmente devido à sua maior proporção de cálcio, que é considerado um elemento antagonista ao ferro no metabolismo.

Dessa forma, mesmo com a fortificação do leite, não se obteve valores elevados de ferro, ou ao menos nas quantidades esperadas para suprir as necessidades diárias deste nutriente na alimentação. Portanto, há a necessidade de indicar suplementação ou introduzir na alimentação de crianças após os seis meses de idade e para mulheres em suas diversas fases do ciclo reprodutivo, outras fontes alimentares que forneçam concentrações mais elevadas, a fim de prevenir doenças a exemplo da anemia ferropriva ${ }^{18}$.

Faz-se necessário destacar que determinados segmentos da população não têm acesso a esses tipos de produtos, tendo em vista seu maior custo de mercado, e talvez até dificuldade de aquisição por não se encontrar disponível em todas as regiões e comércios. Também a falta de quantidades e variedades de marcas suficientes para o consumidor escolher, inclusive esta concorrência facilitaria a probabilidade de se estabelecer preços diferenciados e mais competitivos com os leites não fortificados.

Tabela 4. Teores de ferro (mg/L) em leite fortificado bovino e medidas estatísticas.

\begin{tabular}{|c|c|}
\hline Parâmetro & Ferro \\
\hline Média & 0,86 \\
\hline Erro padrão & 0,11 \\
\hline Mediana & 0,65 \\
\hline Modo & 0,65 \\
\hline Desvio padrão & 0,57 \\
\hline Variância da amostra & 0,32 \\
\hline Curtose & 3,35 \\
\hline Assimetria & 2,12 \\
\hline Intervalo & 2,10 \\
\hline Mínimo & 0,45 \\
\hline Máximo & 2,55 \\
\hline
\end{tabular}

Isso ocorre devido ao processo tecnológico de produção ser mais exigente quanto ao grau de especialização das empresas processadoras de produtos diferenciados, ficando assim, restrito a poucos empresários que podem investir em tecnologias. Porém, se algumas das metas da saúde pública, e consequentemente dos governos, é reduzir cada vez mais a prevalência das carências nutricionais no país, poderia haver um incentivo maior para a produção e disponibilização de alimentos fortificados no mercado, reduzindo os custos aos fabricantes.

\section{Conclusões}

Em geral, os leites fortificados e não fortificados estão dentro das normas de qualidade estabelecidas pelo Ministério da Agricultura, Pecuária e Abastecimento, dando um enfoque maior ao leite enriquecido, que esteve adequado conforme ao descrito nas embalagens. Os leites fortificados com o elemento cálcio é uma boa opção para complementação deste mineral, bem como em relação ao ferro, visto que são elementos essenciais ao bom funcionamento do organismo humano e animal. Observou-se uma quantidade maior do mineral cálcio nas amostras analisadas.

A prática de enriquecimento ainda não é muito comum nas pequenas indústrias de laticínios, devido ao custo benefício e especificidade tecnológica exigida, uma vez 
que é obrigatório confirmar a quantidade do nutriente acrescido. Essa análise tem um custo muito alto, bem como o equipamento de quantificação. Por outro lado os técnicos precisam ser mais qualificados para trabalhar a formulação.

Há boas perspectivas de mercado, com a inserção de tecnologias e inovações para enriquecer os alimentos. Sugere-se o maior envolvimento das indústrias, órgãos fiscalizadores e governo no desenvolvimento dessas novas opções para a população.

Espera-se com essa nova forma de alimentação, a suplementação e enriquecimento, uma ingestão melhor e mais adequada, conferindo quantidades necessárias desses nutrientes. Dessa forma, poderá haver maiores probabilidades de reduzir as carências nutricionais relacionadas aos minerais estudados, que constituem questões relevantes para minimizar a prevalência dessas patologias na saúde pública do país.

\section{Referências Bibliográficas}

1. BRASIL. Ministério da Agricultura, Pecuária e Abastecimento. Secretaria de Defesa Agropecuária. Regulamento de Inspeção Industrial e Sanitária de Produtos de Origem Animal. Brasília: Secretaria de Defesa Animal, 2007. 381p.

2. Cecchi, H. M. Fundamentos teóricos e práticos em análise de alimentos. 2. ed. Campinas: Unicamp, 2003.

3. Behmer, M. L.A. Tecnologia do leite. 13. ed. São Paulo: Nobel, 2004.

4. Angelis, R.C., Ctnas, M.L.B. Biodisponibilidade de ferro na alimentação infantil. São Paulo: Serviço de Informação Científica. Nestlé, 1993. 53p.

5. Veisseyre, R. Lactologia técnica: composición, recogida, tratamiento y transformación de la leche. 2. ed. Zaragoza: Acribia, 1988.

6. Pinheiro, A. J. R.; Mosquim, M. C. A. V. Processamento de leite de consumo. Departamento de Tecnologia de Alimentos. UFV: Viçosa, 1991.

7. Ramalho, R. A., Saunders, C. O papel da educação nutricional no combate às carências nutricionais. Rev. Nutr., 2000, 13, 1, 11-16.

8. Sichieri, R., Coitinho, D. C., Monteiro, J. B., Coutinho, W. Recomendações de alimentação e nutrição saudável para a população brasileira. Arq. Bras. Endocrinol. Metab., 2000, 44, 3, 227-232.

9. Gava, A. J. Princípios de Tecnologia de Alimentos. São Paulo: Nobel, 2002. 284 p.

10. Tronco, V. M. Manual para inspeção da qualidade do leite. 2. ed. Santa Maria: UFSM, 2003.

11. Gonçalves, J. R. Determinação de metais pesados em leite integral pasteurizado no Estado de Goiás. 1999. 80 f. Dissertação (Mestrado em Ciências Animais) - Escola de Veterinária, Universidade Federal de Goiás, Goiânia.
12. Gonçalves, J. R., Mesquita, A. J., Gonçalves, R. M. Determinação de metais pesados em leite integral bovino pasteurizado no Estado de Goiás. Ciênc. Anim. Bras., 2008, 9, 2, 365-374.

13. BRASIL. Ministério da Saúde. Agência Nacional de Vigilância Sanitária. Regulamento Técnico sobre a Ingestão Diária Recomendada (IDR) de proteína, vitaminas e minerais. Resolução RDC n²69. Brasília: Diário Oficial da União, 2005.

14. INSTITUTE OF MEDICINE. Food and Nutrition Board. Dietary Reference Intakes. Washington DC: National Academic Press, 2003.

15. Cobayashi, F. Cálcio: Seu papel na nutrição e saúde. Compac. Nutr., 2004, 05, 02.

16. Kajishima, S., Pumar, M., Germani, R. Efeito de adição de diferentes sais de cálcio nas características da massa e na elaboração de pão francês. Ciênc. e Tecnol. de Aliment., 2003, 23, 2, 222-225.

17. Lanzillotti, H. S., Lanzillotti, R. S., Trotte, A. P. R., Dias, A. S., Bornand, B., Costa, E. A. M. M. Osteoporose em mulheres na pósmenopausa, cálcio dietético e outros fatores de risco. Rev. Nutr., 2003, 16, 2, 181-193.

18. Oliveira, M. A. A., Osorio, M. M. Consumo de leite de vaca e anemia ferropriva na infância. J. Pediatr., 2005, 81, 5, 361-367.

19. Zancul, M.S. Orientação nutricional e alimentar dentro da escola: formação de conceitos e mudanças de comportamento. 2008. 130f. Tese (Doutorado em Ciências Farmacêuticas) - Faculdade de Ciências Farmacêuticas, Universidade Estadual Paulista, São Paulo.

20. BRASIL. Ministério da Agricultura, Pecuária e Abastecimento. Instrução Normativa n. 68. Métodos Analíticos Oficiais Físic -Químicos para Controle de Leite e Produtos Lácteos. Brasília: MAPA, 2006.

21. Tolonen, M. Vitaminas y minerales em la salud y la nutrición. Zaragoza: Espanha. 1995. 278 p.

\section{Berchó Franco', Divino Carlos', Edilaine Santos', José Rubens Gonçalves' \& Renata M. Gonçalves 2*}

${ }^{1}$ Faculdade de Tecnologia SENAI Roberto Mange, CEP 75113-630, Anápolis-GO.

${ }^{2}$ Empresa de Assistência Técnica e Extensão Rural Estado de Goiás (EMATER). Centro de Treinamento, Rodovia R2, quadra, área, lote AR-3, Campus II-UFG, CEP 74690-815, Goiânia-GO. Responsável pela correspondência.

*e-mail: renata.nut@gmail.com 